Original article

\title{
Counting stillbirth in a community - To understand the burden
}

\author{
Bharti Sharma $^{\mathrm{a}}$, Ankit Raina ${ }^{\mathrm{b}}$, Vijay Kumar ${ }^{\mathrm{c}, *}$, Premananda Mohanty ${ }^{\mathrm{c}}$, Minakshi Sharma ${ }^{\mathrm{c}}$, \\ Amit Gupta ${ }^{\mathrm{c}}$
}

a Postgraduate Institute of Medical Education \& Research, Chandigarh, India

${ }^{\mathrm{b}}$ Project MyNT, New Delhi, India

${ }^{\mathrm{c}}$ Survival for Women and Children Foundation, Panchkula, Haryana, India

\section{A R T I C L E I N F O}

\section{Keywords:}

Stillbirth

Stillbirth rate

Stillbirth surveillance

Accredited social health activist (ASHA)

Mobile phone technology

\begin{abstract}
A B S T R A C T
Introduction: There is huge inequality in stillbirth rates across the globe, between high and low income countries, rural and urban population. There is a large discrepancy in the reporting of stillbirth burden and estimated. This study was conducted to count the stillbirth in rural areas of two districts of Haryana, irrespective of place of delivery and to determine the geographical variations in the stillbirth occurrence.

Methodology: Population based stillbirth surveillance was conducted over a period of 32 months (September 2015-April 2018). It was a part of a collaborative effort with Haryana state that comprised of strengthening of home based post natal care by the use of mobile technology in which ASHA report all pregnancies and child births to Survival of women and Children foundation.

Results: During study period, 77336 deliveries were recorded from a population of 1.5 million. Total of 1327 stillbirth ( $>28$ weeks of gestation) were identified with the stillbirth rate of 18.3 per 1000 total births. Overall institutional delivery rate was $92.8 \%$; only $6.3 \%$ of total stillbirths delivered at home and $0.9 \%$ on the way. Conclusion: The present study provides a simple model for reporting and investigation of stillbirth irrespective of place of occurrence through the use of mobile phone. This study has shown a high stillbirth rate in spite of high institutional delivery rate. It emphasizes the need to address the reasons for delay in accessing the health care and quality of care being given rather than just by promoting institutional births.
\end{abstract}

\section{Introduction}

The global burden of stillbirths is very high. Almost 3 million families are affected by stillbirths every year. ${ }^{1-4}$ Though there have been considerable decline in maternal, infant child and neonatal mortality, the decline in stillbirth has not kept pace with other indicators. Despite this slow pace of decline, stillbirths have received very little importance globally until recently. Stillbirths were not included as a target in millennium development goals. ${ }^{5}$ Even though reduction of stillbirths has been mentioned in Every newborn action plan (ENAP) it was not emphasized adequately. ${ }^{6}$ As per lancet every year, almost $98 \%$ of world's total burdens of stillbirth (2.6 million) occur in low-income and middle-income countries and $60 \%$ of them occur in rural areas. ${ }^{7}$ In 2015 the estimated stillbirth rate of India was 23 per 1000 total births and India has the highest number of stillbirths in the world. ${ }^{8}$ For the same year (2015) according to SRS India stillbirth rate was only 4 per 1000 total births. ${ }^{9}$ There is a huge discrepancy in reporting and estimations.
This indicates that in spite of mandatory birth and death registration, whatever stillbirth data we have may be grossly under reported. Stillbirths occur everywhere, i.e. at home, on the way to the facility, or in the facility. In the facilities stillbirth occur in private hospitals and government hospitals. Unfortunately the reporting is variable and a large number of stillbirths are often not reported.

Reporting of stillbirth even from the hospitals has numerous challenges. These include lack of uniformity of definition, even though WHO recommends stillbirth is a baby born after 28 weeks of gestation or weighs more than $1000 \mathrm{~g}$ or has a length of more than $35 \mathrm{cms}$ for international comparisons. ${ }^{10}$ There is a lack of widespread recognition that it is important to assess signs of life at the time of birth, estimate the gestational age correctly and at the minimum weigh each child and determine whether the child was dead born or live born (any signs of life). In order to plan preventive strategies, it is important to know the type of stillbirth - antepartum or intrapartum, and assess the external appearance of each stillbirth to be used as a proxy for this assessment.

\footnotetext{
* Corresponding author. Survival for Women and Children Foundation, Sector 16, Panchkula, Haryana, 134113, India.

E-mail address: 1940kumarv@gmail.com (V. Kumar).
} 
Taking this into consideration WHO now advocates the application of minimum perinatal indicators since the factors that lead to perinatal deaths are common to stillbirths. ${ }^{11}$

The issue of stillbirth is important to address since it is an important indicator of quality of obstetric care and system response. In the ENAP the goal for India is to reduce the stillbirth rate to $12 / 1000$ by the year $2030{ }^{6}$ A minimum starting point to achieve this target would be to count the stillbirth in the population accurately in order to develop a reliable understanding of the trends in stillbirth and obtain important leads for public health interventions. This descriptive study was conducted with the objective to count all stillbirths in rural areas in two districts of Haryana irrespective of place of occurrence by using standard definitions and to determine the geographical variations in the occurrence of stillbirth.

\section{Methodology}

The present study was a population based stillbirth surveillance, conducted in two districts of Haryana, Ambala and Yamuna Nagar with an estimated rural population of 1.5 million (Census of India 2011). Urban areas were not covered since these were not fully served by ASHAs - (Accredited social health activist) over a period of 32 months (September 2015-April 2018). The reporting of data was a part of a collaborative effort that comprised of strengthening of home based post natal care (HBPNC) by the use of mobile technology in which ASHAs report all pregnancies and child births to Survival for Women and Children (SWACH) foundation by mobile phones. ${ }^{12}$ SWACH Foundation located in Panchkula district of Haryana is a non-profit organization working in field of reproductive maternal, newborn and child health. More than 1650 ASHAs have been provided CUG (Closed User group) sims by National Health Mission (State of Haryana) and they have been given standard formats for reporting to Survival of women and Child (SWACH) foundation.

The reporting of pregnancies, child births including all miscarriages, stillbirths, live births and neonatal deaths is done daily. The report is obtained by SWACH foundation staff. The information is consolidated and monitored on a daily basis by a doctor and a manager (social scientist). There are 10 community development blocks in the two districts. The reporting is entered on a web based platform prepared by National health mission of Haryana. ASHAs who delay reporting are contacted on phone and the data is monitored each day. All still births and neonatal deaths were included in the study. Stillbirth was defined as per the world health organization (WHO) definition; birth of a baby with no signs of activity with gestational age of more than 28 weeks or birth weight of more than $1000 \mathrm{~g}$ or a length of more than $35 \mathrm{~cm}$. In this study gestational age according to last menstrual period was recorded in all cases and and birth weight was recorded wherever available. Neonatal death was defined as death of a baby who showed any sign of life after being born. Both these definitions are mentioned since it was important to separate neonatal deaths from stillbirth.

Within 3-4 days of occurrence of stillbirth the staff at SWACH contacts the family on phone to offer condolence and after the informed consent the information related to the stillbirth or neonatal death was taken subsequently. All stillbirths were investigated within 4 weeks of occurrence. The information include district, Community Health center Primary health center village mother's name, phone contact number, last menstrual period, date of delivery, place of delivery, type of delivery, sex and weight was recorded and transferred to excel file which is stored in the internal storage system of SWACH foundation. Separate excel file has been prepared for each community health center and is shared with all concerned staff. Descriptions are obtained from families and ASHAs are recorded separately in Excel file. Each reported and investigated stillbirth is reviewed by a team at SWACH comprising of the investigator, supervisor and a doctor to verify completion of information in each case. In the study data was obtained from the excel sheets maintained under SWACH foundation and presented in frequency and proportions. No further statistical evaluation was done since it is a descriptive study.

\section{Results}

From September 2015-April 2018, 77336 deliveries were recorded from the two districts of Haryana with a population of 1.5 million. Total of 1327 stillbirth ( $>28$ weeks of gestation) were identified and out of them 1228 cases who were fully investigated were included in the analysis (Fig. 1). The mean stillbirth rate of 10 identified blocks of two districts was 18.3 per 1000 total births, ranging from 14.7 per 1000 to 25.2 per 1000 births (Fig. 2). Out of the ten blocks four (Barara, Bilaspur, Khizrabad and Sadhaura) reported a stillbirth rate of more than 20 per 1000 births. Overall institutional delivery rate was $92.8 \%$ in the study area, except in block Khizrabad from where maximum numbers of home deliveries were reported. Otherwise only $6.3 \%$ of total stillbirths delivered at home and $0.9 \%$ on the way (during transportation).

Characteristics of stillbirth (Table 1) Out of 1228 stillbirths, 15.6\% were reported as macerated on the basis of description given by parents and health care providers whereas $3.4 \%$ of cases had no idea about the appearance of fetus at birth. The common words used for describing maceration were "sada gala, badbudar" (rotten), "foola hua" (swollen), "Chhilla hua" (peeled off skin), "jala hua" (burned out) etc. Weight was done in $53.7 \%$ of stillbirth and $10.5 \%$ of them were very low birth weight babies (less than $1500 \mathrm{gm}$ ). Half of these stillbirth were of term gestation ( $>37$ weeks) and $5.4 \%$ of all stillbirths were found to have lethal or visible birth defects at the time of birth. Most of these stillbirths were born vaginally, and only $10 \%$ had cesarean section. The proportion of male Stillbirths was higher than female and in $1.7 \%$ of cases; sex of baby could not be identified. Out of total stillbirths, $10 \%$ were delivered in tertiary care hospitals and $30 \%$ at secondary level (districts hospitals) and $43.6 \%$ in private hospitals.

\section{Discussion}

A simple phone based reporting system has been put in place by which information about the occurrence of stillbirth and neonatal deaths are reported by ASHAs irrespective of place of occurrence of stillbirth in an ongoing manner. The feasibility of reporting stillbirth over a period of 32 months has been demonstrated in the present study. There are a large number of ASHAs deployed by the national Health Mission GOI as a frontline health care worker. Efforts are needed to evolve the similar systems for reporting in order to understand the burden of stillbirth and their trends in the country. ${ }^{13}$ This could be a first step towards achievement of goals of Indian newborn action plan INAP (stillbirth rate of 10/1000) and SDG. ${ }^{14,15}$

In this study the stillbirth rate ranges between 14.7 and 25.2 per 1000 births, comparable to the stillbirth rate of Haryana (20.8-23.8 per 1000 births) reported in lancet in 2018 in a population based prospective cohort study. ${ }^{16}$ The lower levels of stillbirth reported in the present study cannot be compared since the situation is different in different districts in the state depending on their level of development and health system. In this study there was marked variation at block levels which may be explained by different population characteristics and geographical areas. The blocks (Bilaspur, Khizrabad and Sadhaura) with high Stillbirth rate were less accessible and less number of health care facilities as compared to rest of the blocks. The people of these three blocks were poorer and a substantial proportion of population was belonging to minority group. Noon Altijani et al. have also reported increased odds of stillbirth among minority group (Muslim and Christian women). This might be due to cultural constraints or inequalities in health system, or poor socioeconomic strata of minority groups. ${ }^{17}$ Additional system support is required in underserved and high risk areas to reduce the burden of stillbirth.

Birth weight of the baby is an important and most accessible perinatal indicator which can be used as a proxy for viability especially in 


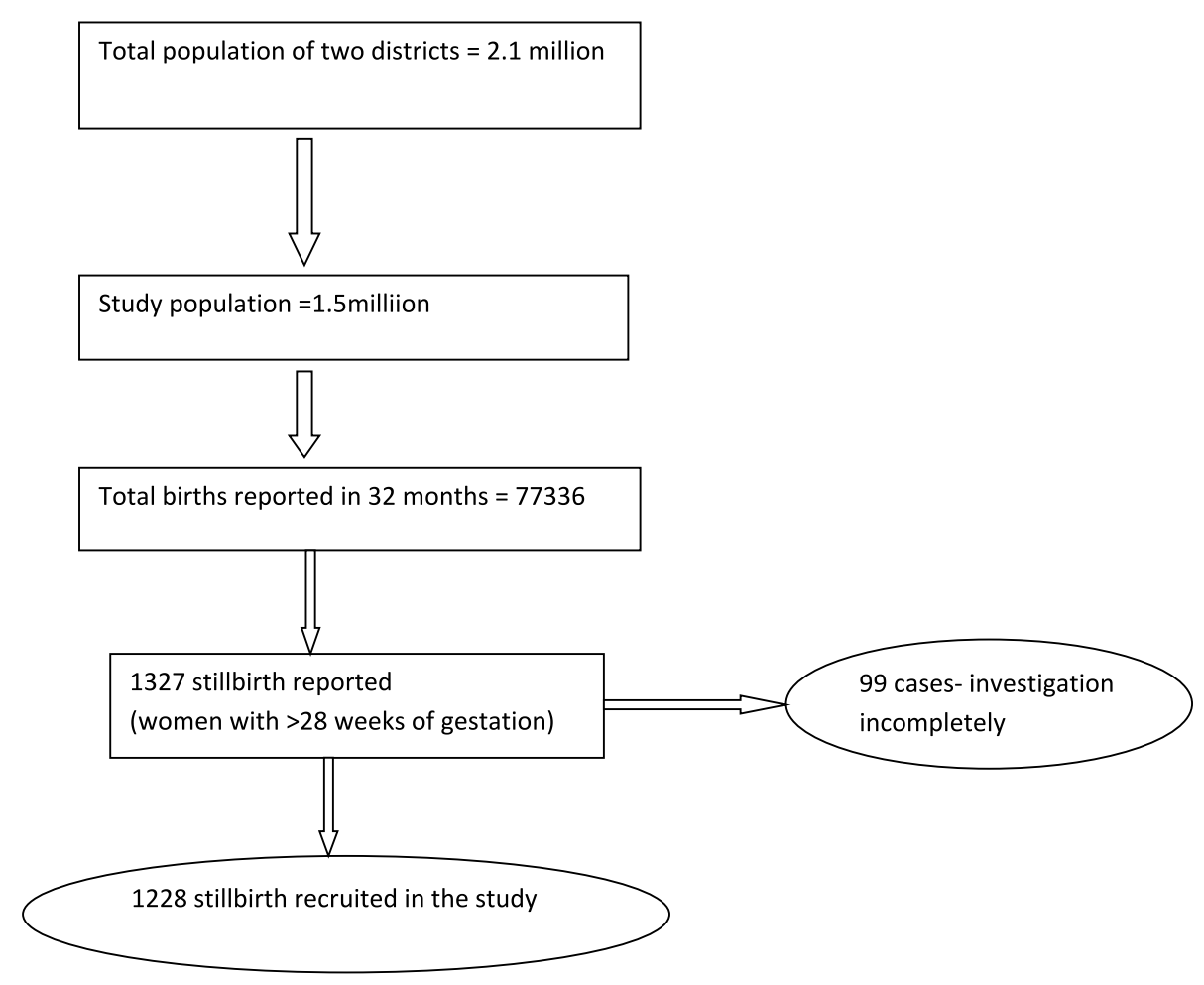

Fig. 1. Flow chart summarizing study population.

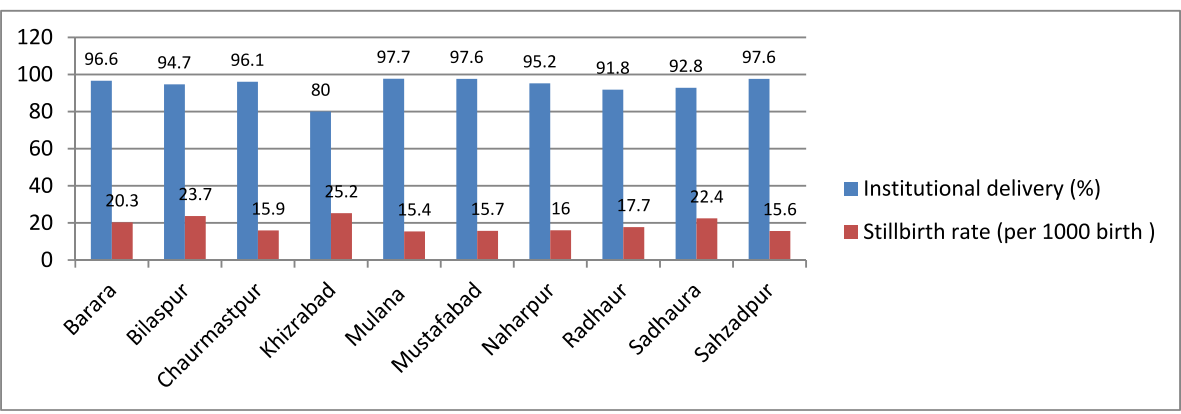

Fig. 2. Block wise distribution of stillbirth rate and proportion of institutional delivery rate of stillbirths.

cases where gestational age is not available or reliable. Birth weight also tells about the proportion of low birth weight babies either related to prematurity or fetal growth restriction. In present study we could succeed in collecting the weight of $53.6 \%$ (659) of total stillbirths. Although there are very few population based studies from LMIC, however in well designed studies also stillbirths were not weighed. ${ }^{18,19}$ Although weighing machines are provided and weighing each newborn is common in institutional deliveries, the importance of weighing still born babies is not widely understood. There is a need to promote weighing of all newborn babies irrespective of their status (live born or still born). This recommendation would contribute to a better understanding about stillbirth. It has been found that even for weighing a stillborn baby there are hurdles of social taboos and culture barriers. ${ }^{19}$ Furthermore there is reluctance amongst the health care provider and families to weigh stillborn and this would be more difficult in babies who are born at home or on the way. Fortunately in this study there were very few births at home or on the way to the hospital. There is significant improvement in institutional delivery rate over years and present study have also shown $>90 \%$ of institutional delivery rate even in rural area. ${ }^{20}$ Out of 659 stillbirths (where birth weight was available), $56 \%$ of them had normal birth weight $(>2500 \mathrm{~g}$ ) and rest all were of low birth weight. One reason for the missing birth weights in the present study is that child birth takes place in different institutions in the private and public sector and awareness about the importance of recording birth weights may not be uniform. There should be provision of weighing balance in labour rooms in all the facilities where deliveries occur.

We could investigate successfully 1228 cases out of 1327 stillbirth reported $(92.5 \%)$ and were able to differentiate fresh stillbirth from macerated on the basis of description provided by the family and ASHA on phone independently. Majority of these stillbirths were fresh stillbirths $(80.6 \%)$, which indicate the probability of very high intrapartum stillbirth rate. This finding is similar to the estimated stillbirth rates in South Asia and Sub Saharan Africa which suggest more than half are intrapartum. ${ }^{21}$ However in a recent population based prospective study from South Asia and Sub Saharan Africa in which verbal autopsies were done for each death, antepartum stillbirth (56\%) were found to be higher than intrapartum deaths $(44 \%){ }^{22}$ This indicates that the timing of stillbirth is crucial and by making assumption on the basis of appearance of fetus at the time of birth is not enough to know the exact timing of death i.e. intrapartum (after the onset of labour) or antepartum (before the onset of labour). Population based studies should include deeper investigation of stillbirth in order to clarify whether the still born 
Table 1

Characteristics of stillbirths.

\begin{tabular}{|c|c|}
\hline Variable & $\begin{array}{l}\text { Number (proportion) } \\
\mathrm{N}=1228\end{array}$ \\
\hline \multicolumn{2}{|l|}{ Type of Stillbirths } \\
\hline Fresh (Intrapartum stillbirths) & $994(80.9 \%)$ \\
\hline Macerated (antepartum stillbirths) & $192(15.6 \%)$ \\
\hline \multicolumn{2}{|l|}{ Reporting of birth weight } \\
\hline Available & $659(53.7 \%)$ \\
\hline$<1500 \mathrm{~g}$ & $69(10.5 \%)$ \\
\hline $1500-2500 \mathrm{~g}$ & $218(33.1 \%)$ \\
\hline$>2500-3000 \mathrm{~g}$ & $372(56.4 \%)$ \\
\hline Not available & $569(46.3 \%)$ \\
\hline \multicolumn{2}{|l|}{ Sex of stillborns } \\
\hline Male & $696(56.7 \%)$ \\
\hline Female & $511(41.6 \%)$ \\
\hline Not identified & $21(1.7 \%)$ \\
\hline \multicolumn{2}{|l|}{ Birth defects } \\
\hline Present & $67(5.4 \%)$ \\
\hline Not present & $1084(88.2 \%)$ \\
\hline No information & $77(6.4 \%)$ \\
\hline \multicolumn{2}{|l|}{ Mode of delivery } \\
\hline Vaginal delivery & $1101(89.9 \%)$ \\
\hline Cesarean & $126(10.3 \%)$ \\
\hline No information & $1(0.1 \%)$ \\
\hline \multicolumn{2}{|l|}{ Place of delivery } \\
\hline Private hospitals & $536(43.6 \%)$ \\
\hline Government Hospitals & $604(49.1 \%)$ \\
\hline Tertiary Care & $124(10.1 \%)$ \\
\hline Primary/Secondary/District hospital & $480(39.0 \%)$ \\
\hline Home & $77(6.3 \%)$ \\
\hline On the way (during transportation) & $11(0.9 \%)$ \\
\hline
\end{tabular}

was likely antepartum or intrapartum since many intrapartum stillbirth can be saved through better management of labour.

Even though there were more than $90 \%$ institutional deliveries in the present study and institutional deliveries should be accompanied with lower stillbirth rate, this has not happened in this study. It means that in spite of institutional delivery, women were not provided optimal care or reached late. In low resource settings having a hospital delivery or skilled attendant at birth does not equate to availability of emergency obstetrics care at each place. ${ }^{23}$ For reduction of stillbirth there is requisite for provision of timely quality service i.e. safe delivery (SBA), provision of timely cesarean section availability of blood transfusion and ability of staff to resuscitate babies. Our estimates indicate that there were seven institutions in the two districts who met the criteria of Comprehensive Emergency Obstetric and New born Care (CEmONC) Services in the government sector. ${ }^{24}$

Out of 10 identified blocks, facility of cesarean is available in only four places and blood bank or backup is available almost an hour distance in the geographical areas covered. Out of 1228 stillbirth, only $10 \%$ of mothers could reach tertiary care hospitals rest all were delivered in district hospitals, community health centers, primary health centers or private hospitals. Cesarean section is one of the important components of emergency obstetrics care and in Haryana state cesarean rate reported in urban area is $13.6 \%$ and $10.6 \%$ in rural area which is much higher than the rate which is considered enough to reduce the stillbirth and maternal mortality associated with prolonged labour. ${ }^{25,26}$ The overall cesarean rate was $22 \%$ in the study area. Therefore Cesarean section was not a limitation in the quest for reduction of stillbirth rate in the community.

\section{Conclusion}

In Low middle-income country like India Community based surveillance to count all stillbirths is feasible and ASHA worker can provide information on vital events including stillbirth as a starting point. It is vital to look for the actual burden of stillbirths, its trends and geographical variation in order to develop the appropriate preventive strategies. The present study provides a simple model for reporting and investigation of stillbirth through the use of mobile phone using verbal autopsy. Greater precision is required to make count reliable especially with respect to gestation age, weight and timing of stillbirth. This study have shown a high stillbirth rate in spite of high institutional delivery rate which emphasizes the need to address the reasons for delay in accessing the health care and quality of care being given rather than just by promoting institutional births. There is genuine need of rationalization and regionalization to provide high quality intra partum care by skilled birth attendant and back up with comprehensive obstetric care for better outcome.

\section{Financial support}

Nil.

\section{Declaration of competing interest}

There are no conflicts of interest.

\section{Acknowledgment}

We would like to acknowledge WHO SEARO Team and DD Child health and community process Coordinator Haryana for the support.

\section{References}

1 Cousens S, Stanton C, Blencowe H, et al. National, regional, and worldwide estimates of stillbirth rates in 2009 with trends since 1995: a systematic analysis. Lancet. 2011. https://doi.org/10.1016/S0140-6736(10)62310-0. published online April 14.

2 WHO. Neonatal and Perinatal Mortality - Country, Regional and Global Estimates 2004. Geneva, Switzerland: World Health Organization, Department of Making Pregnancy Safer; 2007.

3 Stanton C, Lawn JE, Rahman H, Wilczynska-Ketende K, Hill K. Stillbirth rates: delivering estimates in 190 countries. Lancet. 2006;367:1487-1494.

4 Lawn JE, Blencowe H, Pattinson R, et al. For The Lancet's Stillbirths Series steering committee. Stillbirths: where? When? Why? How to make the data count? Lancet. 2011. https://doi.org/10.1016/S0140-6736(10)62187-3. published online April 14.

5 UN. General Assembly Resolution 55/2 United Nations Millennium Declaration. New York, NY: United Nations; 2000.

6 World Health Organization. Every Newborn: An Action Plan to End Preventable Deaths.

7 Lawn JE, Blencowe H, Waiswa P, et al. Stillbirths: rates, risk factors, and acceleration towards 2030. Lancet. 2016 Feb 6;387(10018):587-603.

8 Blencowe H, Cousens S, Jassir FB, et al. National, regional, and worldwide estimates of stillbirth rates in 2015, with trends from 2000: a systematic analysis. Lancet Global Health. 2016 Feb 1;4(2):e98-108.

9 Estimates of Mortality Indicators http://www.censusindia.gov.in/vital_statistics/SRS _Report_2015/8.Chap\%204_Mortality\%20Indicators-2015.pdf.

10 WHO. ICD-10: International Statistical Classifi Cation of Diseases and Related Health Problems - Instruction Manual. vol. 2. Geneva, Switzerland: World Health Organization; 2004.

11 World Health Organization. Making Every Baby Count: Audit and Review of Stillbirths and Neonatal Deaths.

12 Sharma B, Raina A, Kumar V, Mohanty PN, Sharma M, Gupta A. Strengthening homebased postnatal care of rural area of two districts of Haryanausing mobile phone technology: a pilot study. Indian J Community Fam Med. 2021;7:135-139.

13 Altijani N, Carson C, Choudhury SS, et al. Stillbirth among women in nine states in India: rate and risk factors in study of 886,505 women from the annual health survey. BMJ Open. 2018 Nov 1;8(11), e022583.

14 Sharma D. India newborn action plan. J Res Med Sci. 2015;2:58.

15 Assembly G. Sustainable Development Goals. SDGs), Transforming Our World: the. vol. 2030. 2015.

16 Ahmed I, Ali SM, Amenga-Etego S, et al. Population-based rates, timing, and causes of maternal deaths, stillbirths, and neonatal deaths in south Asia and sub-Saharan Africa: a multi-country prospective cohort study. Lancet Global Health. 2018 Dec 1;6 (12):e1297-e1308.

17 Penn N, Oteng-Ntim E, Oakley LL, Doyle P. Ethnic variation in stillbirth risk and the role of maternal obesity: analysis of routine data from a London maternity unit. BMC Pregnancy Childbirth. 2014 Dec;14(1):404.

18 McClure EM, Wright LL, Goldenberg RL, et al. The global network: a prospective study of stillbirths in developing countries. Am J Obstet Gynecol. 2007;197, 247.e1247.e5.

19 Stanton C, Lawn JE, Rahman H, Wilczynska-Ketende K, Hill K. Stillbirth rates: delivering estimates in 190 countries. Lancet. 2006 May 6;367(9521):1487-1494.

20 McClure EM, Wright LL, Goldenberg RL, et al. The global network: a prospective study of stillbirths in developing countries. Am J Obstet Gynecol. 2007 Sep 1;197(3), 247-e1. 
21 Lawn JE, Blencowe H, Waiswa P, et al. Stillbirths: rates, risk factors, and acceleration towards 2030. Lancet. 2016 Feb 6;387(10018):587-603.

22 Ahmed I, Ali SM, Amenga-Etego S, et al. Population-based rates, timing, and causes of maternal deaths, stillbirths, and neonatal deaths in south Asia and sub-Saharan Africa: a multi-country prospective cohort study. Lancet Global Health. 2018 Dec 1;6 (12):e1297-e1308.

23 Cnattingius S, Bergstrom R, Lipworth L, Kramer MS. Pre-pregnancy weight and the risk of adverse pregnancy outcomes. N Engl J Med. 1998;338:147-152 [PubMed: 9428815].
24 Otolorin E, Gomez P, Currie S, Thapa K, Dao B. Essential basic and emergency obstetric and newborn care: from education and training to service delivery an quality of care. Int J Gynecol Obstet. 2015 Jun;130:S46-S53.

25 Paxton A, Maine D, Freedman L, Fry D, Lobis S. The evidence for emergency Obstetric care. Int J Gynaecol Obstet. 2004;88:181-193 [PubMed: 15694106].

26 WHO. The World Health Report 2005: Making Every Mother and Child County. Geneva: World Health Organization; 2006; 2005. Available at:http://www.who.int/whr /2005/en/index.html. 